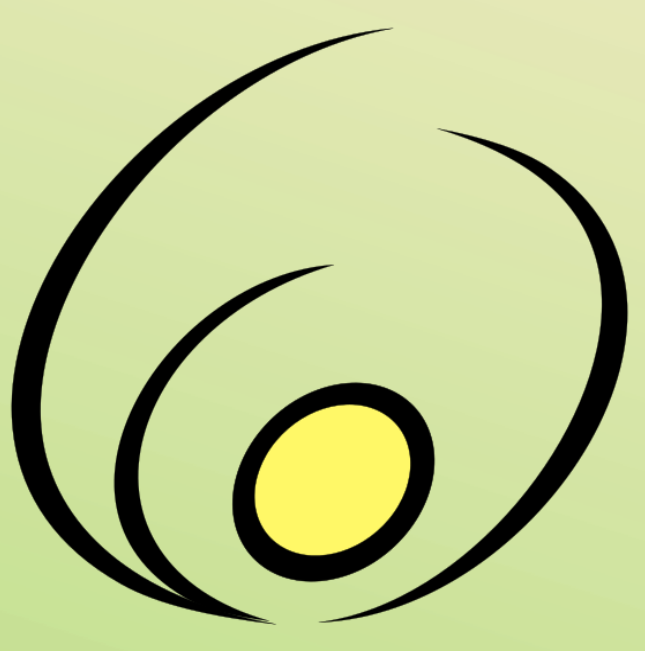

Fórum de

\section{Pró-Reitores}

de Extensão

\section{das Instituições}

\section{Públicas de}

\section{Educação Superior}

\section{Brasileiras}

Revista Brasileira de Extensão Universitária

v. 9, n. 3, p.135-146, set.- dez. 2018 e-ISSN 2358-0399

DOI: https://doi.org/10.24317/2358-0399.2018v9i3.8544

\title{
Escola e comunidade: pesquisa e extensão em busca da cidadania emancipatória
}

Leonardo Bis dos Santos ${ }^{1}$

Antônio Donizetti Sgarbi

Resumo: Parece não haver resistência de que a aproximação entre a comunidade escolar e a do bairro é desejável, contudo, esbarramos muitas vezes nas condições materiais e na apropriação do tempo na forma de prioridades. Neste relato de experiência apresentamos uma proposta de ensino, pesquisa, extensão e mobilização para ação em curso em um bairro periférico da cidade de Vitória/ES. As propostas relatadas são resultado de um esforço conjunto entre servidores de uma escola municipal, do Instituto Federal do Espírito Santo - IFES e de moradores do bairro Jesus de Nazareth, num esforço recíproco e constante na promoção da ressignificação social positiva. Aspectos teóricometodológicos da obra de Paulo Freire - significação do outro - em debate com o conceito de reconhecimento social de Axel Honneth são basilares para a interpretação teórica dos aspectos empíricos - ação dos sujeitos - em busca da emancipação social dos agentes.

Palavras-chave: Resistência Social, Emancipação Social, Educação Popular, Ensino em Periferias

1. Sociólogo, Doutor em História. Professor permanente do Programa de Pós-Graduação em Ensino de Humanidades - PPGEH IFES - Campus Vitória. Líder do Grupo de Estudos, Pesquisas e Extensão em Sociedade e Emancipação - GEPESE. Avenida Vitória, 1729, Jucutuquara CEP: 29.040-780, Vitória/ES - IFES - Campus Vitória - Programa de Pós-Graduação em Ensino de Humanidades - PPGEH. leonardo.bis@ifes.edu.br (autor para correspondência)

2. Filósofo, Doutor em Educação. Professor permanente e coordenador do Programa de Pós-Graduação em Ensino de Humanidades - PPGEH - IFES - Campus Vitória. Líder do HISTOFIC - História e Filosofia da Ciência. donizetti@ifes.edu.br 


\title{
School and community: research and extension in search of emancipatory citizenship
}

\begin{abstract}
It seems there is no resistance to the fact that the approximation between the school community and the neighborhood is desirable. However, we usually tend to come across the material conditions and time appropriation as priorities. On this experience report, we show up an ongoing proposal of teaching, research, extension and social mobilization at a specific peripheral neighborhood in the city of Vitória, Espírito Santo State, Brazil. The proposal described here are the result of a joint effort among the professionals of a municipal school, as well as the Instituto Federal do Espírito Santo - IFES, and residents of the Jesus de Nazareth neighborhood. These three groups worked together in order to promote a positive social resignification. Theoretical and methodological aspects of Paulo Freire's work - the signification of the other - in the debate with the concept of social recognition by Axel Honneth, are fundamental to the theoretical interpretation of the empirical aspects - subjects' actions - searching the social emancipation of the agents.
\end{abstract}

Keywords: Social Resistance, Social Emancipation, Popular Education, Teaching at Peripheral Neighborhoods

\section{Escuela y comunidad: investigación y extensión en busca de la ciudadanía emancipadora}

Resumen: Parece que no hay resistencia de que la aproximación entre la comunidad escolar y la del barrio es deseable, sin embargo, chocamos muchas veces en las condiciones materiales y en la apropiación del tiempo en forma de prioridades. En este relato de experiencia presentamos una propuesta de enseñanza, investigación, extensión y movilización para la acción del curso en un barrio periférico de la ciudad de Vitória / ES. Las propuestas relatadas son el resultado de un esfuerzo conjunto entre servidores de una escuela municipal, del Instituto Federal de Espírito Santo - IFES y de habitantes del barrio Jesús de Nazareth, en un esfuerzo recíproco y constante en la promoción de la resignificación social positiva. Los aspectos teórico-metodológicos de la obra de Paulo Freire - significación del otro - en debate con el concepto de reconocimiento social de Axel Honneth, son fundamentales para la interpretación teórica de los aspectos empíricos - acción de los sujetos - en busca de la emancipación social de los agentes.

Palabras-clave: Resistencia Social, Emancipación Social, Educación Popular, Enseñanza en Periferias

\section{Introdução}

Os parceiros das ações: situando o leitor a respeito do problema abordado

O bairro Jesus de Nazareth reúne características comuns de qualquer bairro de periferia: tráfico de drogas; grande número de moradores desempregados ou ocupando funções subqualificadas e desvalorizadas no mercado de trabalho; alta demanda por serviços públicos de saúde e educação; alta demanda por serviços de assistência social de baixa, média e alta complexidade nos CRAS (Centros de Referência de Assistência Social) e CREAS (Centros Especializados de Referência de Assistência Social); moradias construídas em locais irregulares, com risco de desabamento principalmente em períodos de chuva (tratase de um bairro constituído no entorno e em cima de uma formação rochosa). Enfim, vários problemas sociais comumente ligados à ausência do poder público.

Contudo, em termos geográficos não podemos nos remeter ao conceito de periferia, uma vez que o bairro Jesus de Nazareth está localizado em uma região central, que abriga grande concentração de órgãos públicos - sedes da Polícia Rodoviária Federal, do Departamento Nacional de Infraestrutura de Transporte (DNIT), da Secretaria Estadual de Segurança Pública, além de ficar bem próximo da Prefeitura Municipal e da Câmara de vereadores da cidade e a aproximadamente $1,5 \mathrm{~km}$ de distância da sede da Assembleia Legislativa Estadual, do Tribunal de Contas da União, do Tribunal de Contas do Estado e do Tribunal de Justiça do Espírito Santo, apenas para citar os mais relevantes - e bairros de classe média e alta da capital do estado do Espírito Santo.

Em termos históricos, ligados ao planejamento urbano da cidade de Vitória, está contextualizado na região que foi pensada no final do século XIX no projeto denominado Novo Arrabalde.

O Novo Arrabalde era um projeto de expansão urbana da antiga cidade de Vitória. Foi criado em 1895 pelo governo de Moniz Freire, por meio da Comissão de melhoramentos da Capital. Presidida por Saturnino de Brito, essa comissão teria a função de encontrar um local apropriado para a expansão do sítio urbano, demanda vislumbrada por Moniz Freire para a grande praça comercial que este enxergava existir no futuro (QUINTÃO, 2015, p. 45-46).

De fato, a visão de futuro de Moniz Freire se concretizou e a região planejada agrega atualmente algumas das 
principais repartições públicas, o shopping mais antigo e um dos maiores do estado, além de atrair empreendimentos comerciais e residenciais. Por outro lado, a ocupação do bairro Jesus de Nazareth obedeceu uma lógica diferente: completamente reversa ao conceito positivista e higienista de planejamento urbano presente no Novo Arrabalde, a constituição do bairro se deu primordialmente pelo viés da resistência social.

Apesar do planejamento de Moniz Freire datar de fins do século XIX, a região norte da ilha de Vitória só passaria por grandes transformações na segunda metade do século XX. A movimentação de cargas no Porto de Vitória passaria por uma transformação profunda na sua pauta de mercadorias e, em 1956, o café, que até então era a principal mercadoria exportada, cai para segundo lugar, perdendo para o minério de ferro (SANTOS; RIBEIRO, 2013).

Essa mudança representa uma transição econômica que influenciou profundamente os contornos da cidade de Vitória. Da mesma maneira como ocorre com a cidade do Rio de Janeiro, a capital do estado do Espírito Santo conta com grandes extensões de aterros que alteraram sensivelmente o desenho natural da cidade. Esse período de expansão urbana frente à baía de Vitória e manguezais da região marca o início da ocupação do bairro Jesus de Nazareth. Consta na história divulgada no sítio oficial da Prefeitura Municipal de Vitória que:

Data de 1954, a construção da primeira moradia, localizada na "Prainha" de propriedade do Sr. Clemente Gonçalves da Costa (falecido) e Sra. Djalma da Costa que ainda reside no mesmo local da ocupação inicial. [...] A ocupação se deu de forma desordenada, espontânea, gradual e conflituosa ${ }^{1}$.

Os aterros da década de 1950 em Vitória "criaram" várias novas áreas de ocupação, bem como passagens secas. Uma destas proporcionou a ocupação do bairro por trabalhadores atraídos pelas grandes obras de engenharia civil em curso na cidade e arredores. Por esta razão, a infraestrutura necessária para escoamento do minério de ferro gerou uma nova dinâmica econômica, com rebatimentos diretos no surgimento da periferia urbana de Vitória - que inicialmente ocupava os morros e áreas de manguezais $\stackrel{2}{ }$.

O desenho dos acessos e a ocupação do Morro de Bento Ferreira e/ou Morro do Contestado - primeiros nomes do bairro Jesus de Nazareth - se deram sob condições adversas. Além das condições naturais que dificultavam a instalação das moradias (morro com declividade acentuada em algumas partes), bem como a falta de infraestrutura básica (água encanada e energia elétrica), os primeiros moradores enfrentaram confrontos com a ordem municipal. Segundo consta na história do bairro divulgada pela Prefeitura Municipal de Vitória,

[o] processo de ocupação, até o final dos anos 70, foi caracterizado como conflituoso. Nos anos de 1955/1957, o então Prefeito do Município de Vitória, Dr. Adelpho Poli Monjardim, preocupado com o adensamento da área, determinou que a mesma fosse fiscalizada. O controle era efetuado por fiscais que chegavam a área acompanhados por policiais para executar a demolição dos barracos e expulsar os moradores. Nessas ocasiões ocorriam resistências da comunidade em defesa da posse das habitações e seus respectivos lotes. Foi nesta época que se deu a morte do fiscal da Prefeitura.

A intensificação dos assentamentos ocorreu na década de 70, agravando-se a forma desordenada da ocupação do morro. Nesse período foi concretizada uma política de expulsão das famílias, onde "barracos" foram derrubados e incendiados. Mais uma vez, houve confronto da comunidade com policiais, ocorrendo a morte de um morador.

Tal ao ocorrido, o esforço individual pela moradia transformou-se em uma luta coletiva, em busca da permanência dos moradores na área e legalização dos loteamentos ${ }^{3}$.

O elemento da resistência social se fez presente entre os moradores desde a origem do bairro - o que não é muito diferente de várias outras periferias urbanas de Vitória ou mesmo de outras partes do país. As narrativas de resistência, contudo, muitas vezes são camufladas intencionalmente para eliminar a memória coletiva de luta, em busca de assentar um discurso tutelado pelo Estado a partir de seus agentes - o discurso oficial é o de que vereadores e prefeitos levam os aparelhos públicos para os bairros quase que por uma vontade particular, para 'ajudar' os moradores; nesse sentido as placas de inauguração colocadas nos aparelhos públicos, com os nomes das "autoridades", são instrumentos de massificação desse discurso tutelar.

\section{Discussão teórica: resistências sociais e emancipação social}

Segundo Axel Honneth (2003), os conflitos sociais são uma das principais ferramentas de luta política. Os grupos, mesmo que minimamente organizados, definem suas demandas e estabelecem suas estratégias de ação, as quais têm como pressuposto - ora explícito, ora implícito - dar visibilidade ao conteúdo social em questão:

[...] uma luta só pode ser caracterizada de "social" na medida em que seus objetivos se deixam generalizar para além do horizonte das intenções individuais, chegando a um ponto em que eles podem se tornar a 
base de um movimento coletivo (HONNETH, 2003, p. 256).

Tais movimentos são motivados por uma infinidade de conteúdos socioculturais. Nesse sentido, a percepção das condições materiais varia segundo o conteúdo histórico e culturalmente apropriado. Em se tratando das camadas populares (que é o que nos interessa nessa ação de extensão e pesquisa), a percepção das condições materiais tem obedecido a lógicas da expropriação dos saberes - o que Paulo Freire (2016) trata como invasão cultural - e do discurso político tutelado; ou seja, o melhor estilo "o povo não sabe escolher seu caminho, por isso precisa de lideranças que o façam por ele".

Os processos de resistência e protesto social, nesse sentido, são empreendidos no momento em que grupos sociais, dotados de consciência de sua situação, lutam para serem reconhecidos a partir de suas singularidades e demandas coletivas. Essas demandas inevitavelmente são direcionadas ao Estado, que possui a premissa de arbitrar as lutas sociais. Como único ente que possui mecanismos que permitem utilizar legitimamente a força/violência para prover, entre outros, as demandas desejadas pelos movimentos sociais, o Estado assume papel crucial na leitura dos processos de resistência social (MEKSENAS, 2002). Estes movimentos de enfrentamento constantemente conterão graus distintos de conflitos sociais, podendo variar desde os latentes - onde há considerável invisibilidade social da demanda geradora do conflito - até os níveis extremos - em que a integridade física das pessoas envolvidas é atingida (SANTOS, 2014).

Em um ambiente democrático, os conflitos expõem argumentos contraditórios na busca por soluções negociadas. O que temos no Brasil, contudo, é a ausência essencial da negociação política, primordialmente porque as massas não são ouvidas/reconhecidas. Ou melhor, podem até ser ouvidas/reconhecidas, mas não são levadas em consideração quando da definição das prioridades de atendimento de necessidades. Desta forma, o aparelhamento do Estado, pelos interesses econômicos do capital financeiro internacional, relega os dirigentes governamentais nacionais à condição de instrumentos dos negócios, ao invés dos gestores do interesse comum, das vontades populares. Apesar dos inúmeros canais de diálogo que as novas tecnologias da informação permitem, contraditoriamente se proliferam as deficiências das oitivas por parte da maioria dos membros das elites políticas.

O enfrentamento da ordem hegemônica a partir dos instrumentos de luta carece do autoconhecimento e reconhecimento social. Esse reconhecimento opera em duas dimensões distintas, mas inter-relacionadas: interna (dentro da própria comunidade) e externa (de outros grupos sociais em relação à comunidade). As potencialidades da ação coletiva comunitária emergem como pontos centrais na ressignificação social das periferias, criando oportunidades de modelos alternativos de sociedade, mais afetos às necessidades ambientais, culturais e sociais das classes populares. A partir da valorização do saber ouvir e do debate de ideias contrárias, num processo dialógico, poderemos ser capazes de sustentar um modelo de sociedade mais equânime.

Para que essa proposta seja realizada um conceito se revela ímpar: a emancipação. Citar essa palavra isoladamente, contudo, não revela a sua real apropriação para fins de análise, uma vez que pode representar vários aspectos, segundo a área de interesse e o posicionamento político. Por exemplo, o direito à emancipação implica a capacidade de decidir, agir e ter responsabilidade por suas escolhas. Na política empírica, falar em emancipação de um município tem correlata conotação, ao separar um dado território de outro, compondo para isso a estrutura administrativa necessária à administração pública e de atendimento aos munícipes.

Na tradição das ciências humanas críticas, o conceito de emancipação tem na obra Sobre a Questão Judaica, de Karl Marx, um relevante ponto de reflexão. Nessa obra é analisada a situação dos judeus na Prússia - atual território alemão - e Marx conclui que na França da primeira metade do século XIX já havia ocorrido a emancipação política. A este termo era associada a ideia de que o Estado estava emancipado das relações religiosas ao se tornar laico, a partir da Revolução Francesa e da promulgação da Declaração dos Direitos do Homem e do Cidadão, de 1791.

Contudo, Marx (2010) destaca que a emancipação política não foi capaz de promover a emancipação humana, aquela responsável por recuperar a essência do homem/sujeito para além das relações de produção, uma vez que a própria emancipação consistiria na "redução do mundo humano e suas relações ao próprio homem.” Ou seja, a emancipação política resultaria na "redução do homem, por um lado, a membro da sociedade burguesa, a indivíduo egoísta independente, e, por outro, a cidadão, a pessoa moral." (MARX, 2010, p. 54)

Mas a emancipação humana só estará plenamente realizada quando o homem individual real tiver recuperado para si o cidadão abstrato e se tornado ente genérico na qualidade de homem individual na sua vida empírica, no seu trabalho individual, nas suas relações individuais, quando o homem tiver reconhecido e organizado suas "forces propres" [forças próprias] como forças sociais e, em consequência, não mais separar de si mesmo a força social na forma da força política (MARX, 2010, p. $54)$. 
Ao cindir os interesses do homem egoísta em relação aos interesses da comunidade, converter a outra pessoa em obstáculo e não canal de realização de sua liberdade e subordinar todas as relações sociais aos interesses egoístas e individualistas, a sociedade burguesa não realizou a emancipação humana, mesmo tendo realizado a emancipação política (cidadania). Por conseguinte, Marx (2010) coloca como horizonte histórico a emancipação humana como movimento de construção de novas relações sociais.

Reconhecer e organizar suas próprias forças, como nos apresenta Marx, exige do indivíduo a recuperação dos saberes perdidos a partir das relações de produção fragmentadas, baseadas no industrialismo e no capitalismo. A autonomia das escolhas - limitação severa ou mesmo fim da tutela política tal qual temos atualmente - também é uma exigência dessa nova sociedade. Essa reconstrução social passa por uma revalorização das ações e ressignificação das relações comunitárias. Emerge dessa conclusão o objetivo central de fortalecer as relações entre escola e comunidade ${ }^{4}$.

Deveras, a construção e o desenvolvimento de novas relações societais em que o ser humano possa emanciparse como "homem total" se colocam como desafio e possibilidade histórica na e pela práxis humana e não como um desenvolvimento mecânico e linear da história. Em síntese, reconhece-se a necessidade de criar novas relações em que a comunidade local se reencontre consigo mesma, com o outro e com a natureza, desenvolvendo todas as suas potencialidades. Assim, escola e comunidade assumem papel histórico, político e social singular.

[...] Escola e cidade são mundos de tal modo imbricados, como são imbricados alunos, professores e pais [...] imbricados como são, determinam-se mutuamente: a cidade educa a escola e a escola educa a cidade. Na verdade a escola é uma invenção da cidade. A escola é a cidade educando intencional e formalmente seus membros para si mesma [...] As relações e inter-relações que ocorrem na cidade são educativas por si mesmas. A escola, dentro da cidade, promove relações desejadas, estudadas, intencionais [...] (LORIERI, 2006, p. 93).

Nessa linha de pensamento não é possível ver a escola separada do bairro ou da cidade. Uma parceria consciente pode ser uma oportunidade de humanização, em lugares onde os riscos de desumanização são frequentes. Educadores que querem cuidar do ambiente local e escolar podem desenvolver juntos tecnologias sociais que gerem o empoderamento popular e, consequentemente, a humanização das pessoas e dos ambientes. Já existem várias atividades que envolvem escola e outras instituições na comunidade de Jesus de Nazareth, sente-se, portanto, que as lideranças locais, assim como os pais e responsáveis pelos alunos, poderiam ser mais presentes nesta parceria; assim, uma ação de extensão, como a que se propõe neste projeto de pesquisa, pode ser um caminho para o fortalecimento desta parceria e destas ações.

\section{Metodologia: pesquisa e extensão com base nos preceitos da dialogicidade}

A busca pela emancipação social como elemento fundamental para estruturar ações de resistência contrahegemônica, valorizando o saber popular local, exige uma postura científica e política condizente com a teoria debatida. Posturas científicas que tratam "o outro" como objeto de pesquisa, por vezes inclusive buscando um afastamento para garantir neutralidade perante os dados coletados, não são condizentes com a proposta de trabalho aqui apresentada.

A obra de Paulo Freire e a teoria da ação dialógica nos fornece, dessa forma, substrato capaz de interpretar os dados (pesquisa) e propor ações de intervenção social (pesquisa e extensão). Para isso, a construção dos objetivos é realizada conjuntamente com os parceiros da comunidade - escolar e do bairro. Em termos empíricos, comparada com métodos tradicionais, empreende-se maior esforço e energia na etapa de diagnóstico e planejamento. Afinal tem-se que encontrar um ponto central que atenda aos anseios da comunidade e da pesquisa - e seus fundamentos teóricos.

Vale ressaltar que a proposta freireana de partir do diálogo visa valorizar a demanda localizada e o conjunto de saberes ali identificado, mas também não furta os pesquisadores de proporem temáticas com base no conhecimento historicamente consolidado em torno da ciência. Freire destaca que a delimitação temática de um projeto deve se dar em conjunto com a base social à qual se assentará a pesquisa/extensão: "feita a delimitação temática, caberá a cada especialista, dentro de seu campo, apresentar à equipe interdisciplinar o projeto de 'redução' de seu tema." (FREIRE, 2016, p. 160). Tal redução se refere ao fragmento do conhecimento empírico ao qual o especialista está associado por conta de sua formação acadêmica e/ou social. E acrescenta que:

No processo de "redução" deste, o especialista busca os seus núcleos fundamentais que constituindo-se em unidades de aprendizagem e estabelecendo uma sequência entre si, dão a visão geral do tema "reduzido".

$\mathrm{Na}$ discussão de cada projeto específico, se vão anotando as sugestões dos vários especialistas. Estas, ora se incorporam à "redução" em elaboração, ora 
constarão dos pequenos ensaios a serem escritos sob o tema "reduzido", ora uma coisa e outra.

Estes pequenos ensaios, a que se juntam sugestões bibliográficas, são subsídios valiosos para a formação dos educadores-educandos que trabalharão nos "círculos de cultura".

Neste esforço de "redução" da temática significativa, a equipe reconhecerá a necessidade de colocar alguns temas fundamentais que, não obstante, não foram sugeridos pelo povo, quando da investigação.

A introdução destes temas, de necessidade comprovada, corresponde, inclusive, à dialogicidade da educação, de que tanto temos falado. Se a programação educativa é dialógica, isto significa o direito que também têm os educadores-educandos de participar dela, incluindo temas não sugeridos. A estes, por sua função, chamamos "temas dobradiça" (FREIRE, 2016, p. 161).

Dessa forma, passo-a-passo, partimos do diagnóstico comunitário a partir de reuniões agendadas na sede da escola do bairro e da associação de moradores, bem como da observação participante em eventos comunitários. O diagnóstico teve por objetivo identificar e definir os maiores desafios da comunidade, 'o problema', estabelecendo as possibilidades de diversas ações para solucioná-lo.

Passado o primeiro passo, partimos para o processo de planejamento das ações, analisando diversas possibilidades de estratégias que contribuam com a solução do problema identificado. Neste momento foram buscados parceiros junto à instituição de vinculação dos autores deste artigo, a fim de compor uma equipe multidisciplinar para contribuir na resolução das demandas levantadas. O plano de ação foi composto e validado em reunião comunitária e reavaliado periodicamente - bimestralmente ou trimestralmente, dependendo do calendário e agendas individuais.

As ações são traçadas num calendário de dois ou três meses de execução, combinando propostas implementadas na escola e no bairro, sempre envolvendo moradores, alunos e servidores da unidade de educação. Neste processo, aproveita-se toda ocasião para envolver a comunidade. Os pesquisadores especialistas ajudam a criar um ambiente de confiança entre os integrantes da associação e a comunidade escolar. Busca-se conscientizar os membros do grupo, no sentido de uma responsabilidade compartilhada por todos os integrantes.

Como já mencionado, periodicamente as ações passam por avaliação conjunta. Esta etapa tem sido essencial para motivar os integrantes e rever desacertos das ações. Destaca-se a percepção e expectativas dos participantes sobre as atividades, técnicas e resultados obtidos durante o processo.
Durante todo o processo estimula-se a reflexão acerca das ações e os resultados teóricos e empíricos. Nesse sentido, os resultados já alcançados foram tema de apresentação de moradores em seminários realizados no Instituto Federal do Espírito Santo - IFES, com participação ampla de alunos e servidores do Campus Vitória, bem como de convidados externos (Figuras 1-3).

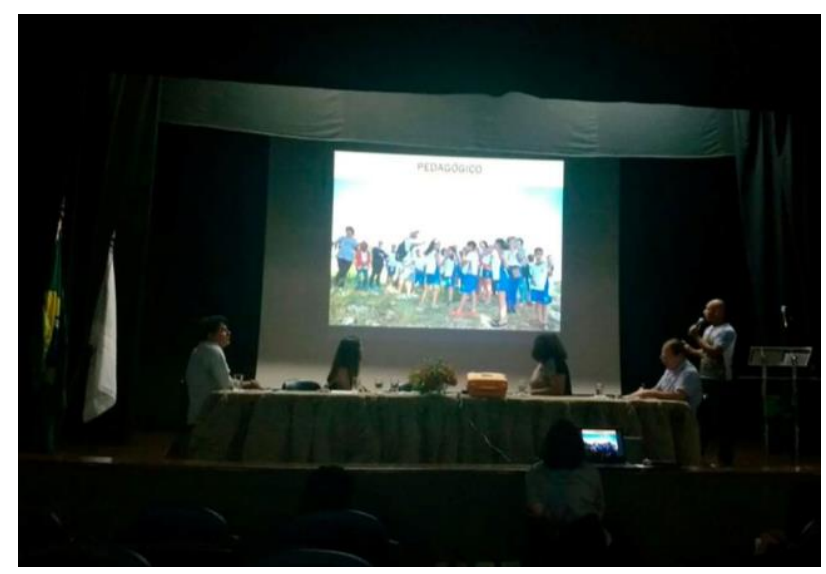

Figura 1. Apresentação de resultados de uma ação na comunidade por morador do bairro em evento ocorrido no IFES - Campus Vitória. Fonte: acervo pessoal dos autores.

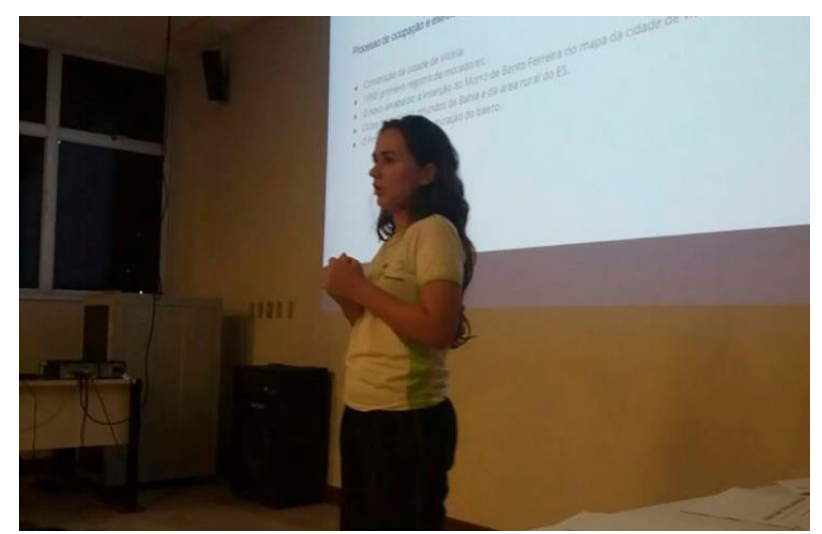

Figura 2. Bolsista de iniciação científica apresentando resultados de pesquisa em evento de educação ambiental no IFES - Campus Vitória. Fonte: acervo pessoal dos autores.

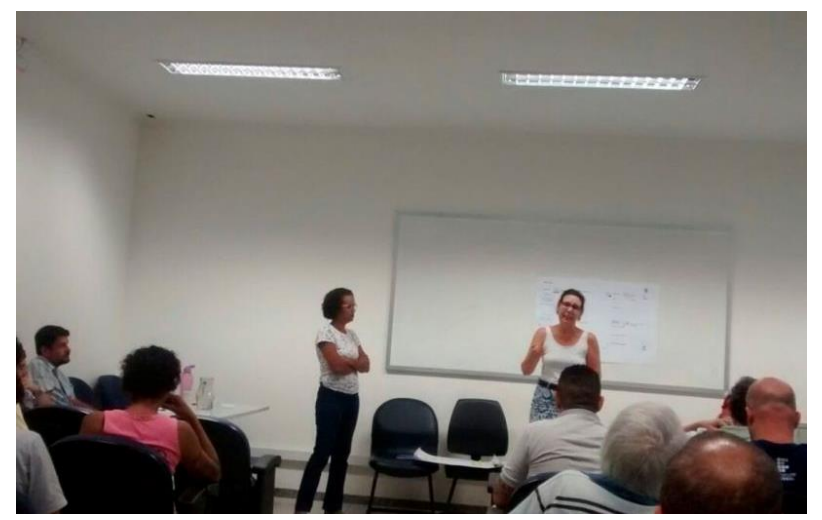

Figura 3. Apresentação de resultados pela diretora e pela pedagoga da escola municipal Edna de Mattos Siqueira Gaudio em reunião do Fórum dos Movimentos Populares do IFES - Campus Vitória. Fonte: acervo pessoal dos autores. 
Dessa forma, os resultados alcançados até aqui foram validados na comunidade e fora dela, contribuindo para o reconhecimento e valorização sociocultural local.

\section{Resultados alcançados: demandas e ações já implementadas}

De modo geral, pesquisadores e moradores do bairro concordam que existe uma demanda que está sempre em pauta: desenvolver o sentimento de pertencimento e envolvimento com o território. Nota-se a necessidade de reforçar a autoestima dos moradores dos bairros onde vivem pessoas de baixa renda em Vitória-ES, socialmente marginalizadas e estigmatizadas, uma vez que os meios de comunicação divulgam continuamente fatos que dão a impressão de que os moradores destes bairros estão todos envolvidos na criminalidade, fatos que só reforçam a criminalização da pobreza, gerando o estigma social. O fato recente que mais marcou o Bairro Jesus de Nazareth, nesse sentido, foi a intervenção feita pelo Estado, há cerca de um ano.

Em 17 de agosto de 2017 uma megaoperação policial, envolvendo homens, viaturas, barcos e helicóptero das polícias militar, civil, federal e rodoviária federal (PRF), parou a região de Bento Ferreira e Jesus de Nazareth (Figura 4).

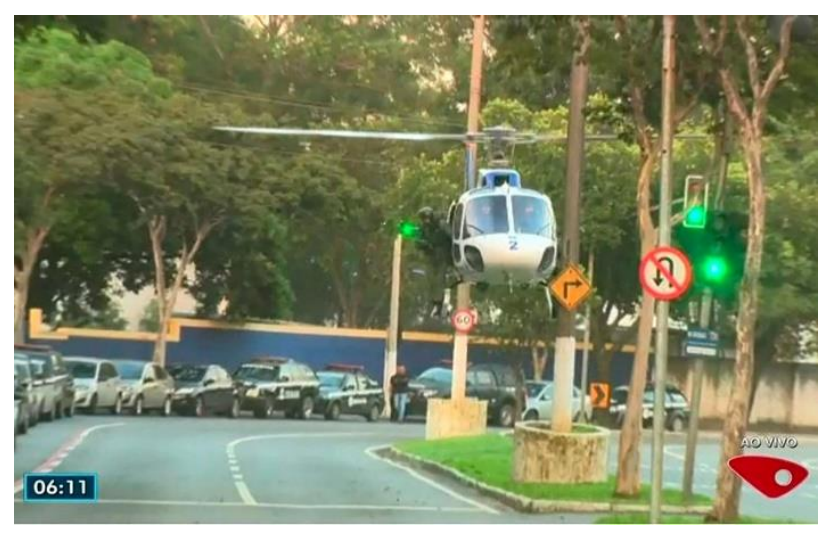

Figura 4 - Helicóptero da Polícia Militar do Espírito Santo em operação no bairro Jesus de Nazareth. Fonte: g1.globo.com ${ }^{5}$

Essa megaoperação teve como objetivo declarado pelas autoridades policiais a busca e apreensão de drogas e armas, bem como eventuais foragidos da justiça. Teve um papel simbólico acentuado, dada a força e recursos aplicados. No final da operação, pelo menos quatro resultados puderam ser percebidos: 1) foram detidas seis pessoas, sendo uma menor, outra por não pagamento de pensão alimentícia, duas foram liberadas logo em seguida por "não oferecer risco à sociedade", terem "residência fixa e ocupação lícita", uma já tinha cumprido pena, tendo assim direito à liberdade; 2) houve severas críticas, pois para se chegar às 6 prisões foram mobilizados 381 militares, o que representou custos operacionais elevados; 3) para a população da cidade de Vitória que conhece pouco o bairro, foi reforçado o estigma de comunidade violenta ${ }^{6}$; 4) a Ordem dos Advogados do Brasil em Vitória considerou a ação um abuso de autoridade e a Comissão de Justiça ${ }^{7}$ e Paz da Arquidiocese de Vitória divulgou nota dizendo que a operação foi "abusiva e prepotente. ${ }^{8}$ "

A sensação de insegurança, comum em comunidades da periferia urbana dos médios e grandes centros, é recorrente entre levantamentos socioantropológicos realizados in loco. Em pesquisas, qualitativas ou quantitativas, são comuns os resultados que apontam a segurança pública como principal problema enfrentado. Este, contudo, não é o caso dos moradores do bairro Jesus de Nazareth, apesar do estigma social que a comunidade carrega, como foi afirmado anteriormente.

A partir das reuniões diagnósticas e das visitas em campo com os moradores, foi possível elencar uma outra questão, a que mais os incomoda: o acondicionamento incorreto de resíduos (lixo).

Dada a declividade e a ausência de ruas em algumas partes do bairro - vários pontos só são acessados via escadarias a coleta de lixo pela Prefeitura Municipal de Vitória é bastante deficitária (Figura 5). Apesar de haver coletas periódicas, o acesso dos garis à parte mais alta do bairro é dificultado, bem como o transporte desses resíduos até a parte acessível a veículos (para captação e transbordo adequado).

Nas visitas in loco foi possível atestar o desconforto que emergia nos discursos captados nas reuniões. Diante das demandas da comunidade local e da comunidade escolar foram desenvolvidos os projetos de extensão e projetos que combinavam extensão e pesquisa de intervenção do tipo participante no bairro e na escola. Nesse sentido, já foram concluídas duas dissertações de mestrado, ambas construíram de forma participativa um produto educativo que foi devolvido à comunidade e outras três estão em andamento.

Os projetos de pesquisa e de pesquisa/extensão se desenvolveram a partir de demandas da comunidade escolar e foram elaborados por estudantes de diversos níveis (médio, técnico, graduação e pós-graduação), lideranças comunitárias, professores da escola do bairro e professores especialistas (mestrandos/as, orientadores). $\mathrm{O}$ primeiro versou sobre a Educação Ambiental e desenvolveu um jogo para conhecer e buscar soluções para os principais problemas ambientais do bairro (jogo que está à disposição dos professores da escola); o segundo tratou da História Local, desenvolvendo um site 
com informações sobre o bairro, administrado pela comunidade escolar ${ }^{9}$. Em conjunto a estes trabalhos, estão sendo desenvolvidas ações de extensão, também contando com a participação da comunidade escolar, que abordam as maiores demandas detectadas na comunidade local.

Como forma de confirmar os dados qualitativos captados, apresentamos o resultado de uma pesquisa quantitativa realizada no bairro, encomendada pelo SEBRAE/ES. Nessa pesquisa, realizada pelo Instituto Futura em maio de 2017, com erro amostral de 4\%, cerca de $38 \%$ dos entrevistados em Jesus de Nazareth apontaram o lixo como principal problema do bairro (25\% limpeza pública e $13 \%$ falta de coleta de lixo). Diante do diagnóstico realizado e validado junto aos moradores passamos às reuniões de definição de ações e de sensibilização de potenciais parceiros internos do Instituto Federal do Espírito Santo (IFES) - Campus Vitória, a fim de compor equipe multidisciplinar.

Como já apontado, as ações tiveram como horizonte teórico o desenvolvimento da emancipação social, desencadeada por ações de professores, equipe pedagógica, pais e alunos da escola Edna de Mattos
Siqueira Gaudio, em parceria com a comunidade do entorno, buscando aprimorar tecnologias sociais mobilização para a ação transformadora. O plano de ação foi construído a partir de atividades propostas pelos sujeitos/parceiros das atividades de pesquisa e extensão.

Diante desse quadro em que o lixo foi diagnosticado como principal problema do bairro (Figura 6), foram traçadas as seguintes ações na escola: implementação de técnicas de plantio de espécies comestíveis e ornamentais como elemento pedagógico (Figura 7); elaboração de pesquisa gravimétrica para classificação e reflexão a partir dos resíduos gerados no bairro ${ }^{10}$.

Está em fase de desenvolvimento um app com o objetivo de valorizar a história local, com enfoque nos processos de resistência e ocupação do bairro. Para questões de demonstração, $2 Q R$ Codes foram criados como imagens gatilhos que abrem uma seção do aplicativo com imagens antigas e atuais sobre dois lugares distintos: Vista de Bento Ferreira e Praia do Suá (ambos vizinhos do bairro Jesus de Nazareth). O aplicativo também conta com uma tela de informações sobre como usar e sobre os desenvolvedores $\underline{11}$ (Figura 8).
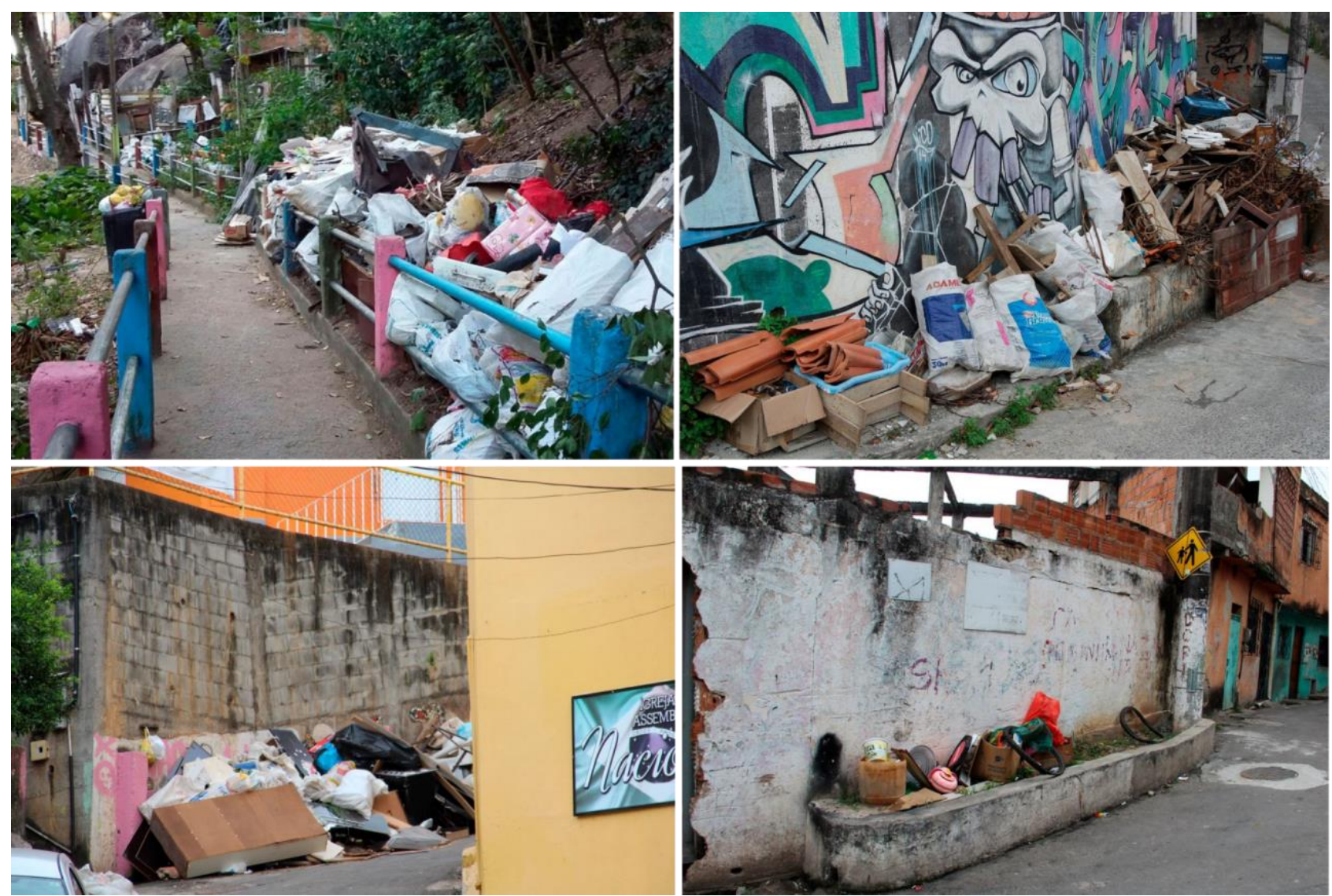

Figura 5. Lixo acondicionado de forma irregular nas ruas do bairro Jesus de Nazareth - resultados da fase diagnóstica. Fonte: acervo pessoal dos autores. 
JESUS DE NAZARETH

(395 entrevistas)

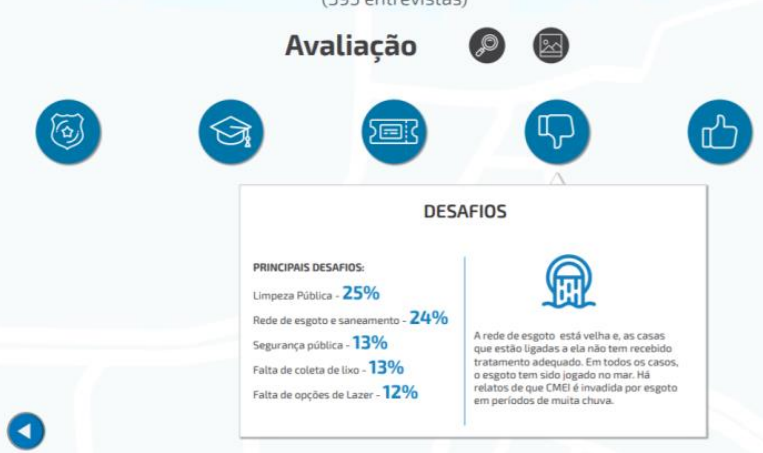

Figura 6. Resultados de pesquisa quantitativa: principais desafios do bairro Jesus de Nazareth. Fonte: Pesquisa Mapa de navegação/SEBRAE Nova sede, elaborada pelo SEBRAE/ES e aplicada pelo Instituto Futura. Cedida gentilmente aos autores deste artigo para fins de pesquisa.

Também foram definidas ações implementadas na comunidade, entre as quais se destacam mutirões de limpeza e pintura de escadarias do bairro, como também o plantio de mudas ornamentais e comestíveis. Nessas ações são envolvidos alunos da escola Edna de Mattos Siqueira Gaudio, bem como moradores do bairro ${ }^{12}$ (Figura 7).

\section{Considerações finais}

As ações de pesquisa e extensão em curso no bairro Jesus de Nazareth têm apresentado um cenário profícuo de parcerias entre IFES e comunidade. Os alunos e pesquisadores do Instituto envolvidos têm a oportunidade de aplicar seus conhecimentos e aprender empiricamente a relacionar teoria e a prática social. Nesse sentido, as ações de pesquisa e extensão têm proporcionado plenamente um de seus principais pressupostos: a vivência dos conhecimentos acadêmicos aplicados na realidade empírica, por parte dos alunos.

Por outro lado, professores e servidores da escola Edna de Mattos Siqueira Gaudio e moradores do bairro estão tendo apoio técnico para mobilização social, projetos de intervenção e práticas pedagógicas diversas (Figura 8), bem como são estimulados a participar das pesquisas e ações de extensão desenvolvidas. Quanto mais agentes envolvidos, mais plural tendem a ser as intervenções.

Muitos obstáculos ainda se colocam para os moradores locais em relação ao lixo. A Prefeitura Municipal de Vitória ainda não encontrou - e parece não estar procurando - uma solução para o recolhimento de resíduos nas partes mais altas do bairro. Na prática, tem agido sob demanda - quando é pressionada pelos moradores, reforçando o argumento da tutela. $\mathrm{O}$ exemplo vem da própria comunidade que tem enveredado esforços próprios para superar suas condições: já podemos elencar diversas áreas recuperadas no bairro, a partir de ações como: o plantio de mudas ornamentais e pinturas de muros e fachadas; mutirões de limpeza dos acessos ao bairro e escadarias; busca por novos hábitos em relação aos resíduos (estímulo ao reuso, acondicionamento correto dos resíduos etc.); e a valorização do saber comunitário e local a partir das manifestações socioculturais $\frac{13}{}$.
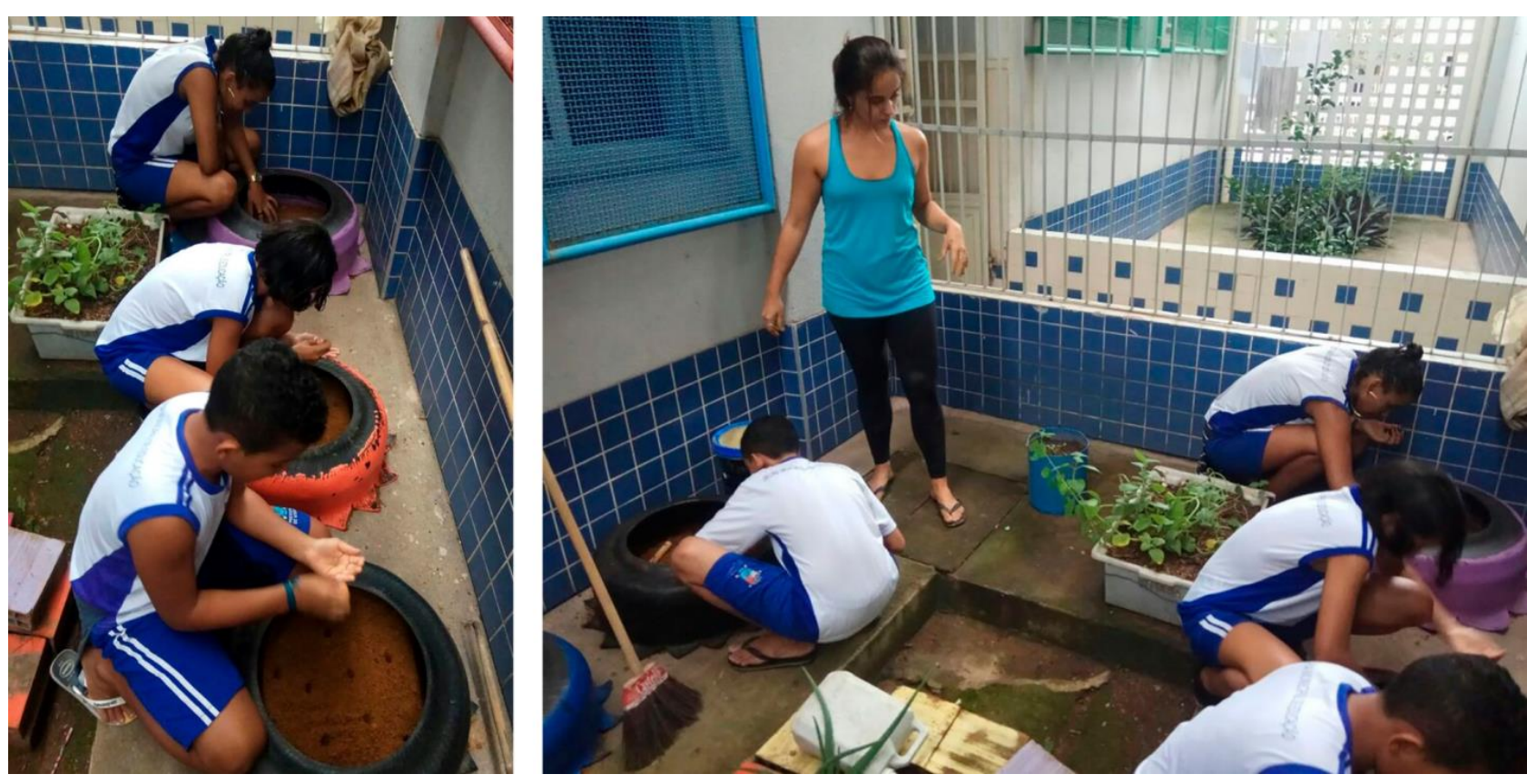

Figura 7. Alunos da escola Edna de Mattos Siqueira Gaudio em aula experimental de técnicas de plantio, conduzidos por bolsista de PIBIC - aluna de engenharia sanitária e ambiental do IFES - Campus Vitória. 

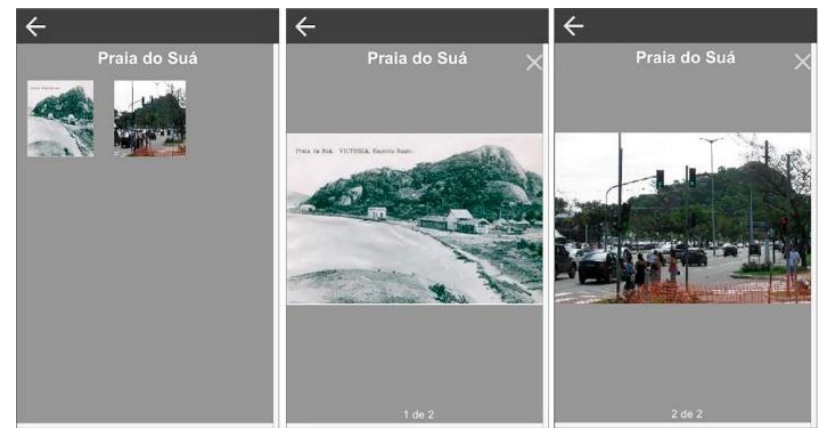

Figura 8. Tela de informações multimídia para o $Q R$ code da Praia do Suá. Fonte: Relatórios parciais de voluntários de ação de extensão (alunos de engenharia elétrica do IFES - Campus Vitória).

Projetos da comunidade, como o Tour no Morro $\frac{14}{}$, que aliam geração de renda, contribuição para a divulgação da história local e ressignificação comunitária, foram e estão sendo apoiados no contexto das ações de pesquisa e extensão contempladas nesse projeto. Para tal, uma semana após a anteriormente citada megaoperação das polícias, desenvolvemos com os moradores um vídeo de promoção do bairro com o auxílio de um drone $\underline{15}$ e divulgado em uma rede social. Em poucos dias havia sido visualizado por milhares de pessoas - muitas delas próprios moradores que desconheciam seu bairro a partir de uma vista aérea.

Os conceitos de emancipação social e de cidadania emancipatória, que aparecem neste trabalho de forma correlata, se estabelecem nos processos de valorização dos saberes e práticas locais, apresentando o potencial de ação coletiva contido nas periferias. Romper o discurso tutelado da política e potencializar as ações comunitárias, a partir da relação entre escola e bairro, tem se mostrado bastante frutífero.
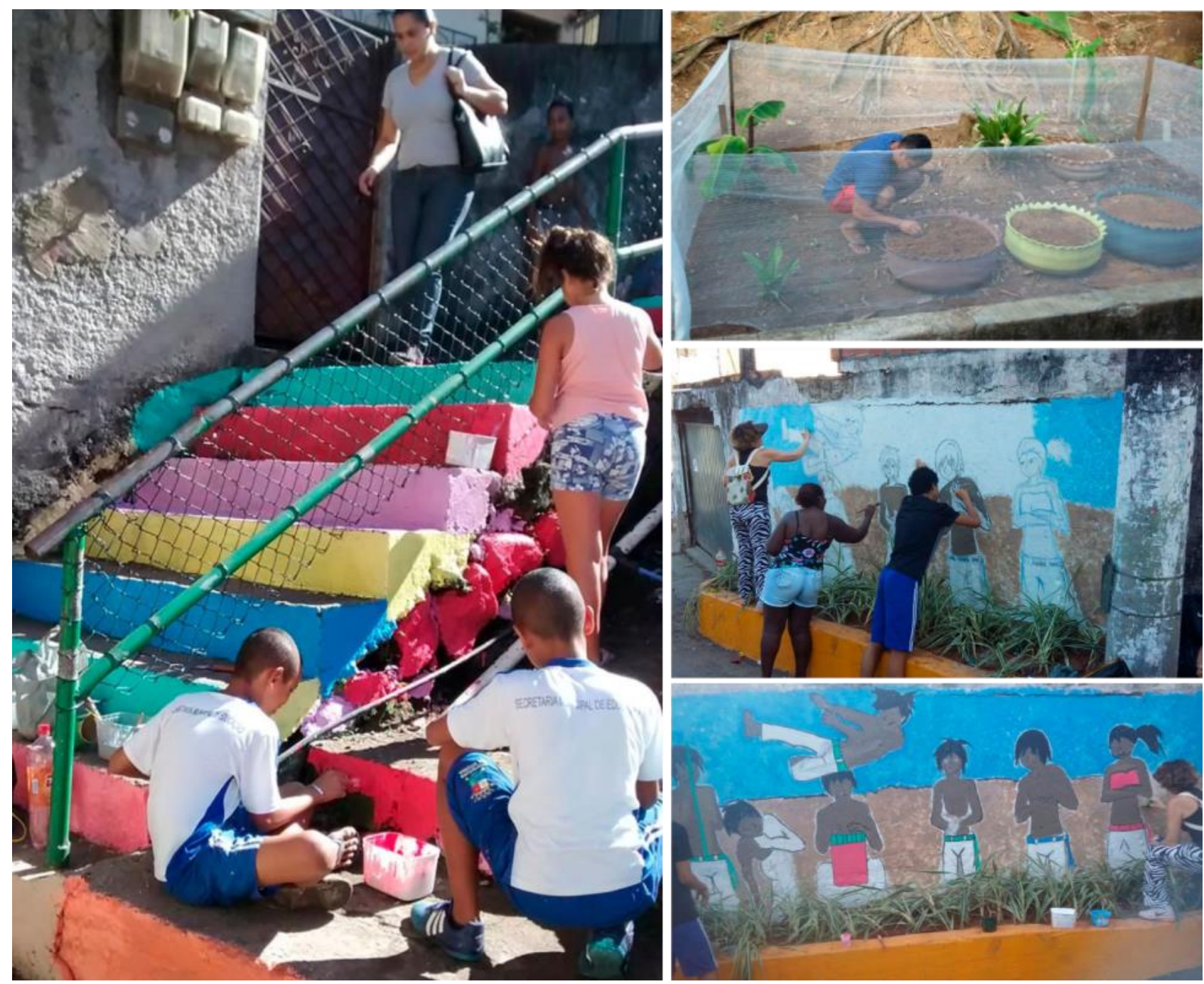

Figura 9. Ações na comunidade de recuperação de áreas de depósito irregular de lixo e pintura de escadarias. Fonte: acervo pessoal dos autores. 
As realizações comunitárias e na escola representam a capacidade de mobilização e de realização dos indivíduos. O empenho de moradores, incomodados com seu contexto, tem sido o combustível para a continuidade das ações. Sabe-se, também, que a mudança social requer procedimentos processuais e contextuais. Emancipar a sociedade frente aos processos de submissão nos quais estamos contidos requer tomada de consciência e incentivo às ações modificadoras, constantemente. Envolver as crianças e adolescentes, bem como as gerações adultas, é essencial e necessário neste trabalho.

\section{Contribuição de cada autor}

Ambos os autores participaram de todas as etapas do projeto e produção do texto.

\section{Notas}

1. Prefeitura Municipal de Vitória. Disponível em: <http://legado.vitoria.es.gov.br/regionais/bairros/regiao3/jes usdenazareth.asp>. Acesso em: Out 2018.

2. Sobre o processo de ocupação da periferia urbana de Vitória, ver o documentário Lugar de toda pobreza, de Amylton de Almeida (1983). Disponível em: < https://www.youtube.com/watch?v=0HeZLv3gQXs $>$. Acesso em: Out 2018.

3. Prefeitura Municipal de Vitória. Disponível em: < http://legado.vitoria.es.gov.br/regionais/bairros/regiao 3/jesusdenazareth.asp _ >. Acesso em: Out 2018.

4. Boaventura de Sousa Santos tem desenvolvido uma proposta de operacionalização do conceito de emancipação social que coloca em debate a capacidade comunitária de enfrentamento dos processos tutelados do Estado. Essa capacidade está relacionada direta ou indiretamente com o reconhecimento positivo de práticas comunitárias (Ver: SANTOS, Boaventura de Sousa. Renovar a teoria crítica e reinventar a emancipação social. São Paulo: Boitempo, 2007). Para isso, parte de uma leitura crítica da obra de Marx, assim como o faz Honneth no contexto de sua teoria do reconhecimento social em que rompe com o mecanicismo vulgar exposto por alguns autores materialistas como Feuerbach. Nesta ação de pesquisa e extensão, resumidamente, partimos da premissa que a emancipação humana tal qual descrita por Marx deve ser perseguida, mas salvo um processo radical em todo o planeta, obedecerá a um percurso que é antecedido pela emancipação social. Esta vem sendo construída historicamente a partir da ecologia de conhecimentos, com o objetivo de promover o reconhecimento positivo no enfrentamento contra-hegemônico, contra as estruturas de dominação, a partir de estratégias de reflexão e ação (FREIRE, 2016; HONNETH, 2003; SANTOS, 2007).

5. < https://g1.globo.com/espirito-santo/noticia/operacao-nomorro-jesus-de-nazare-fecha-a-beira-mar.ghtml >

6. Para obter mais informações sobre os resultados da megaoperação citada ver: < https://g1.globo.com/espirito- santo/noticia/balanco-de-megaoperacao-em-vitoria-e-de-6presos-e-5-armas-apreendidas.ghtml _>; e/ou <

https://www.folhavitoria.com.br/policia/noticia/08/2017/me gaoperacao-em-jesus-de-nazareth-termina-com-seisdetidos-e-armas-e-drogas-apreendidas >; e/ou < http://www.elimarcortes.com.br/2017/08/suspeitos-foramliberados-pela-justica.html >

7. Disponível em: <

https://www.gazetaonline.com.br/noticias/cidades/2017/08/ oab-aponta-crime-de-abuso-de-autoridade-em-operacaoem-vitoria-1014090693.html > Acesso em: Out 2018.

8. Comissão de Justiça e Paz da Arquidiocese de Vitória. Disponível em: < https://www.gazetaonline.com.br/ noticias/cidades/2017/08/abusiva-e-prepotente--dizarquidiocese-sobre-megaoperacao-em-vitoria1014091808.html >. Acesso em: Out 2018.

9. Disponível em: < http://jesusdenazarethes.wixsite.com/memoriajn >.

10. Foi aprovado com contemplação de duas bolsas de iniciação científica pelo Instituto Federal do Espírito Santo - IFES um projeto de pesquisa que visa à elaboração de: a) uma horta escolar como instrumento pedagógico (não se prevê a quantidade produzida, mas sim a experiência proporcionada aos participantes); e b) uma composteira para reuso de matéria orgânica (esta composteira parte da classificação dos resíduos - pesquisa gravimétrica). Duas bolsistas do curso de Engenharia Sanitária e Ambiental foram selecionadas para aturarem na EMEF Edna de Mattos Siqueira Gaudio, todas as sextas-feiras, com um grupo de alunos no contraturno de ensino regular.

11. Para acessar, basta baixar o aplicativo no link < goo.gl/zuZwGu >, desabilitar a segurança para aplicativos que não estão disponíveis no app store e apontar para um dos $Q R$ Codes. Nesse aplicativo está previsto o suporte para imagem, som e texto, de modo que o conteúdo pode ser vasto A partir da disciplina Sociologia e Cidadania, oferecida pelos autores deste artigo ao curso de Engenharia Elétrica do Instituto Federal do Espírito Santo, os alunos foram motivados a desenvolver um projeto que conectasse conhecimentos de Sociologia e Engenharia Elétrica. Entre os projetos foi proposto a criação do app, em desenvolvimento após a conclusão da disciplina.

12. Entre 2017 e 2018 várias ações foram implementadas pela comunidade, definidas em reuniões na EMEF Edna de Mattos Siqueira Gaudio. Pinturas de escadarias, recuperação de espaços de destinação irregular de resíduos e plantio de espécies ornamentais foram as principais ações.

13. Desafio das escadarias. Disponível em: $<$ http://g1.globo.com/espiritosanto/noticia/2015/10/moradores-pintam-escadarias-dobairro-jesus-de-nazareth-em-vitoria.html >. Acesso em: Out 2018.

14. Para mais informações sobre o projeto desenvolvido por um morador do bairro, ver < https://blogdestinoes.com.br/tourno-morro/>, <https://caminhagente.com.br/tour-morrojesus-de-nazareth-vitoria-es/>,

<http://www.descortinandohorizontes.com/2017/07/tourno-morro-jesus-de-nazareth-conhecendo-o-bairro-e-umavista-privilegiada-da-baia-de-vitoria.html $>$ e/ou $\langle$ http://aves.org.br/revista-vitoria-mais/editoria/viva-jesusde-nazareth>.

15. Disponível em: <https://www.youtube.com/watch?v=4Iu0KBssaw>. Acesso em: Out 2018. 


\section{Fontes de dados}

PREFEITURA MUNICIPAL DE VITÓRIA. Vitória em dados. Disponível em: <http://legado.vitoria.es.gov.br/ regionais/bairros/regiao3/jesusdenazareth.asp>. Acesso em: Out. 2018.

SEBRAE. Pesquisa Mapa de navegação/SEBRAE Nova sede. Vitória: Instituto Futura, 2017.

\section{Referências}

FREIRE, P. Pedagogia do Oprimido. 62. ed. Rio de Janeiro: Paz e Terra, 2016.

HONNETH, A. Luta por reconhecimento: a gramática moral dos conflitos sociais. São Paulo: Editora 34, 2003.

LORIERI, M. A. Escola e cidade que se educam. Cadernos Cenpec/Nova série, v. 1, n. 1, p. 85-98, 2006.

MARX, K. Sobre a questão judaica. São Paulo: Boitempo, 2010.

MEKSENAS, P. Cidadania, poder e comunicação. São Paulo: Cortez, 2002.

QUINTÃO, L. do C. Modernização urbana na Belle Époque capixaba: revisitando o Novo Arrabalde. In: RIBEIRO, L. C. M. et al. (Orgs.). Modernização e modernidade no Espírito Santo. Vitória: EDUFES, 2015, p. 13-61.

SANTOS, L. B. dos. O conflito social como ferramenta teórica para interpretação histórica e sociológica. Boletim do Museu Paraense Emílio Goeldi. Ciências humanas, v. 9, n. 2, p. 541-553, 2014.

SANTOS, L. B. dos; RIBEIRO L. C. M. Disputas pelo mar: desenvolvimento e conflitos no litoral e espaço oceânico da costa capixaba. In: SANTOS JÚNIOR, J. L. dos; SANTOS, W. L. P. dos (Orgs.). Desafios do desenvolvimento capixaba no século XXI. Curitiba: Editora CRV, 2013, p. 73-89.
Como citar este artigo:

SANTOS, L. B. DOS \& SGARBI, A. D. Escola e comunidade: pesquisa e extensão em busca da cidadania emancipatória Revista Brasileira de Extensão Universitária, v. 9, n. 3, p. 135146, 2018. Disponível em: < https://periodicos. uffs.edu.br/index.php/RBEU/article/view/8544/pdf $>$ 